\title{
Ali Şir Nevaî Şiirinin Sadık Bey Sadıkî Sanatına Etkisi
}

\author{
Tölqin SULTANOV*
}

\begin{abstract}
$\ddot{O} z$
Homer, Dante, Nizami, Sa'dî, Şekspir, Balzak, Tolstoy ve Tagor gibi büyük sanatçılarla aynı ayarda görülen, Türk Dünyasının en önemli ortak şahsiyetlerinden olan Ali Şir Nevaî, Türk dilinin ve edebiyatının gelişmesinde önemli katkıları olmuş büyük bir ediptir.

Timurlular zamanında Orta Asya'da gelişen Çağatay Edebiyatı'nın en büyük şahsiyeti Ali Şir Nevaî (14411501); XVI. ve XVII. yüzyıllarda Azerbaycan şiirini önemli bir şekilde etkilemiştir. Şairin dilinin, o zamanlarda birçok Türk halkı tarafından kolaylıkla anlaşlabilmesi ve şiirlerindeki insan severlik, derin anlam, yüksek sanat örneği onun eserlerinin geniş bir coğrafyada - tüm Türkistan'ın yanı sıra Azerbaycan, İran, Türkiye ve Hindistan'da - yayılmasına neden olmuştur.

Ali Şir Nevaî’nin şiirlerinde kullandığı konu ve gayeden etkilenerek Azerbaycan'da XV-XVII. yüzyıllarda, Kişverî, Fuzulî, Sadık Bey Sadıkî, Muhammed Âmanî, Şah İsmail Hataî, Rahmetî Tebrizî, Saib Tebrizî, Alican Kövsî Tebrizî, Zafer Murtazakulu Han Şamlı, Vahidi Kazvinî gibi Azerbaycanlı sanatçılar O'nun şiirlerine nazire gazeller, muhammes ve tezkireler yazmışlardır.

Şâh I. Abbâs'ın kitâbdârlığını yürütmesinin yanı sıra ressam ve şairliğiyle tanınan Sâdık Bey Afşar, Türk Edebiyatında da iyi bilinen; Ali Şir Nevaî’nin Çağatay Türkçesi ile yazılmış şâirler tezkiresi “Mecâlisü'nNefâis" etkisi altında yazılan "Mecmau'l-Havas"ın yazarıdır.

"Sadıkî" mahlasıyla, Farsça ile Türkçenin farklı edebî şivelerinde manzum örnekler veren şâir, Türkçe şiirlerini, külliyatındaki şairler tezkiresinden hemen sonra "Kasâyid ü Gazeliyyat-1 Türkî" başlı̆̆ı altında toplamıştır. Sâdıkî, Türkçenin Osmanl, Azerî ve Çağatay edebî şivelerinde ürünler vermiştir. Çağatay Türkçesiyle yazdığı şiirlerinde hem Çağatay hem de Azerî Türkçesi özellikleri görülmektedir.

Sadıkî’nin eserlerinin Tebriz Devlet Kütüphanesinde bulunan külliyatında "Zübdetü'l-kelâm", "Mesnevi" ("Fetihname-i Abbas Nâmdâr"), "Mâkâlât u Hikâyât", "Mesnevi-i Sa'd u Sa'id", "Dîvân-1 Gazeliyyât-1 Pârsîy u Türkî”, "Mecmau'l-Havas", "Manzume-i Kanun us-suverî Nakkaş̂̂”, "Mecmû’a-i Munşe’at u Mekâtibât", "Tezkiretü’ş-şuarâ", "Haziyyât" gibi eserler mevcuttur.

Bu makalede gazel sanatına ait gelenek, edebî etkileşim ve edebî yenilik gibi meseleler Ali Şir Nevaî’nin "Bedâyiü'l-Bidâye" ve Sadık Bey Afşar Sadıkî’nin "Şiirler" adlı divanlarındaki 'Bolmasun' redifli gazelleri örneğinde incelenmiştir.
\end{abstract}

Anahtar Kelimeler: gazel, nazire, lirik kahraman, gelenek, edebî etki, ayrıcalık, maharet, edebî sanatlar.

* Semerkand Devlet Yabancı Diller Enstitüsü, Semerkand, Özbekistan.
Elmek: tolqin82@yahoo.com 


\title{
The Influence of Alisher Navai's poetry on the art of Sadik Bey Sadiki
}

\begin{abstract}
One of the most important personalities of the Turkic-speaking world and considered on equal footing with great artists such as Homer, Dante, Nizami, Sa'di, Shakespeare, Balzac, Tolstoy and Tagor, Alisher Navai is indeed a prominent man of letters who greatly contributed to the development of Turkic language and literature.

As the greatest figure of Chagatai literature that flourished in Central Asia during the Timurid period, Alisher Navai (1441-Hanam1501) also largely influenced Azerbaijani poetry in the subsequent $16^{\text {th }}$ and $17^{\text {th }}$ centuries. The language of the poet, then a very easily understood by the Turkic people, philanthropy in poetry, deep meaning, high art samples has caused his works to be spread in a wide geography in all Turkestan, as well as Azerbaijan, Iran, Turkey and India. Thanks to the intelligibility of his poetry by various Turkic peoples of the time as well as the humanism, profound meaning and elegant artistic nature of his poems, his works, he was able to secure a wide variety of readers from across a vast number of lands, including the entire Turkestan as well as Azerbaijan, Iran, Turkey and India.

Inspired by the themes and subjects in the poetry of Alisher Navai, Azerbaijani artists of the $15^{\text {th }}$ to $17^{\text {th }}$ centuries such as Kishveri, Fuzuli, Sadik Bey Sadiki, Muhammad Amani, Shah Ismail Khatayi, Rahmati Tabrizi, Saib Tabrizi, Alijan Kovsi Tabrizi, Zafer Murtazakulu Shamli and Vahidi Kazvini wrote nazires (parallels), mukhammases (fivesome stanzas) and tezkires (biographical dictionaries).

Known for his skills in painting and poetry as well as his post as the court librarian of Shah Abbas I, Sadik Bey Afshar authored the work "Majma" al-Khawas" under the influence of the well-known Majalis al-Nafais, the tezkire of poets written which Alisher Navai wrote in Chagatai language.

Composing fine pieces of verse in various literary dialects of Persian and Turkic with his pseudonym "Sâdık̂̂", he compiled his Turkic poems under the title "Kasâyid ü Gazeliyyat-1 Türkî", right after his tezkire on poets. Sadiki penned works in the Ottoman, Azerbaijani and Chagatai dialects of Turkic. In the poems he composed in Chagatai Turkic, it is possible to discern the features of both Chagatai and Azerbaijani dialects.

The collection of Sadıkî's works in Tabriz State Library include works such as "Zübdetü'l-kelâm", "Mesnevi" ("Fetihname-i Abbas Nâmdâr"), "Mâkâlât u Hikâyât", "Mesnevi-i Sa“d u Sa“id”, "Dîvân-1 Gazeliyyât-1 Pârsîy u Türkî”, "Mecma“u'l-havâs”, "Manzume-i Kanunu’s-suverî Nakkaşı̂”, "Mecmû'ai Münşe'at u Mekâtibât", "Tezkiretü’ş-şuarâ", "Haziyyât".

This article discusses the problems of tradition, literary influence and innovation in the gazel genre through a comparative analysis of redifs "bolmasun", found in the gazels "Badoyi'ul-bidoya" by Alisher Navoi and "She'rlar" by Sadikbek Afshar Sadiki.
\end{abstract}

Keywords: gazel, nazire, lyric hero, tradition, literary influence, privilege, skill, literary arts. 


\section{Giriş}

Özbek-Azeri edebî ilişkileri çok eski tarihlere dayanmaktadır. Ancak bu ilişkiler Doğu halkları edebiyatının ve bilimsel tefekkürünün gelişmesine büyük etkisi olan, ölümsüz eserleri ile dünya edebiyatında şerefli bir yere sahip büyük sanatçı Ali Şir Nevaî döneminde en yüksek noktaya ulaşmıştır. Nevaî-şinas İsmail Hikmet'in vurguladığı gibi "Nevaî; kendisinden önceki Türk şairlerinden aldığı feyzi kendisinden sonraki sanatçllara fazlasıyla ulaştıran bir şairdir." (Hikmət 1926: 29).

Ali Şir Nevaî sanatının, Azerbaycan'da sevilmesinin ve geleneklerinin devam ettirilmesinin esas sebebi; Nevâ̂’nin Nizamî Gencevî, İmadeddin Nasimî, Hakanî Şirvanî, Şah Kasım Envar gibi seleflerinden öğrendiklerine sadık kalarak insanı her şeyden üstün bilmesi, Türk dilinin gelişmesi için mücadele etmesi, şiirlerinde zahiri ve batıni güzellikleri övmesi, halkın arzu ve isteklerini ortaya koyması, aşkı müşahade yoluyla sıfatlamış olmasıdır.

Azerbaycanlı ünlü Nevaî uzmanı Cennet Nagiyeva, Nevaî sanatının Azerbaycan edebiyatına etkisi meselesini üç döneme ayırarak inceler:

1. XV-XVII. yüzy1llar.

2. XVIII-XIX. yüzyıllar.

3. XX. yüzyıldan günümüze kadar olan dönem (Nağıyeva 2001: 7).

Her dönemde Nevaî üslubunun farklı türlerdeki şekillerinden etkilenen şairler bulunmaktadır. Bilhassa, XV. yüzyılda Kişverî, XVI. yüzyılda Fuzulî, Sadık Bey Sadıkî, Muhammed Âmanî, Şah İsmail Hataî, XVII. yüzyılda Rahmetî Tebrizî, Saib Tebrizî, Alican Kövsî Tebrizî, Zafer Murtazakulu Han Şamlı, Vahidi Kazvinî gibi Azerbaycanlı sanatçılar, Ali Şir Nevâ̂’nin eserlerindeki gâye ve karakterlerden esinlenerek nazire gazeller, muhammes ve tezkireler yazmışlardır.

XVI. yüzyılın ikinci yarısı ve XVII. yüzyılın başlarında Azerbaycan'da yaşam sürmüş olan Sadık Bey Afşar ünlü bir şair, maharetli bir yazar, metin bilimci, hattat ve minyatür ustasıdır. Sadıkî mahlası ile şiir yazmıştır. Ali Şir Nevaî'nin sanat üslubu ve poetik maharetinden ilham alarak eşsiz nazireler ve ayrıca tezkire yazmış ilk Azeri şairdir. Azerbaycan tezkire yazarı Muhammed Ali 
Terbiyet'in itiraf ettiğine göre, Sadıkî'nin “Mecmau 'l-Havas” tezkiresi Nevaî’nin “Mecâlisü’n-Nefâis" eseri üslubunda, Azerbaycan dilinde yazılmıştır. Tezkirede, XVI-XVII. yüzyılda yaşayan 480 sanatçı hakkında bilgi ve onların sanatından örnekler sunulmuştur. (Tərbiyat 1987: 280). Yalnız, Sadık Bey Sadıkî’nin 2008 yılında Azerbaycanlı Ekrem Bagirov tarafindan hazırlanan "Mecmau'l-Havas" adlı eserini incelediğimizde tezkirenin giriş, 369 şairin hayatı ve sanatı hakkında bilgi sunan sekiz mecmua ve sonsözden ibaret olduğu anlaşılır (Әfşar 2008).

Sadıkî'nin hayatı ve sanatı üzerine çalışmalarını gerçekleştiren Azerbaycanlı Mantıka Muradova'nın kaydettiğine göre, onun 587 gazelinden 40'1 Türkçedir (Muradova 1999: 66-67).

Sadıkî Afşar'ın Azerice, Özbekçe ve Türkçe gazelleri ilk defa Turhan Gancey tarafından araştırılmıştır. Turhan Gancey "Sadıkî Afşar 'ın Türkçe Şiirleri " adlı makalesinde Sadıkî’nin Doğu Türkçesinde 7 ve Batı Türkçesinde 5 gazelinin olduğunu kaydetmiştir (Gandjei 1971: 19-26). Sadıkî divanını yayıma hazırlayan Paşa Kerimov'un kaydettiği üzere külliyatta, "Kasâid u gazeliyât-ı Türkî" başlıklı 2 kasidesi, 40 gazeli, 1 sakînâmesi, 1 terkib-i bendi, 1 kıtası bulunmaktadır (Әfşar 2010: 8). Mehmet Nuri Çınarcı da 2012 yılında yayımladığ1 "Sâdıkî-i Efşârın Tebriz Milli Kütüphanesindeki Külliyatı ve Türkçe Manzumeleri" adlı makalesinde önceki yayımlara alınmayan Türkçe şiirlerinden örnekler sunmaktadır (Çınarcı 2012: 813-835).

Sadık Bey Afşar Sadıkî Tebriz'de II. Şah İsmail döneminde saray kütüphanesinde çalışmıştır. Daha sonra Şah Abbas döneminde "kitapdar" ünvanına layık görülür. Bu sırada Orta Asya şairleri, bilim adamları, hattatları, ressamlarının eserlerini, ayrıca da Ali Şir Nevaî’nin eserlerini Nesta'lik yazısına çevirmiştir.

Sadıkî, Ali Şir Nevaî sanatıyla yakından tanışarak onun eserlerinden esinlenmiştir; Nevaî gâyeleri, üslubu ve simgelerinden yararlanarak Azerbaycan dilinde "Mecmau 'l-Havas" adlı tezkiresini, Türkçe ve Farsça mektuplardan ibaret olan "Münşeat"1nı ve "bolmasun”, "bolğay koşki”, "cananing - dermaning", “canımğa-üstihanımğa", "etding”, "imiş”, "koşki”, körmeyin", "ile”, "meni-seni”, “ot”, "kalmadı", "kamati-kıyameti”, “subh”, "tutar - gülüzar”, “üçün”, “vida” gibi anlamca zengin, şekilce kusursuz nazireler yazmıştır. 
Aşağıda Ali Şir Nevaî’nin “Bedâyiü’l-Bidâye” (Navoiy 1987a: 431-432.) ve Garâibü's-Siğâr (Navoiy 1987b: 371.) adlı divanlarında yer alan "bolmasun" redifli gazeliyle Sadık Bey Afşar Sadıkî’nin yazdığı "bolmasun” redifli nazireyi (Hikmət 1926: 29.) (Ofşar 2010: 49.) tür, edebî sanatlar, gâye ve simgeler açısından karşılaştırarak Özbek şiir geleneklerinin Azerbaycan şairinin sanatına etkisi meselesini aydınlatmaya çalışalım.

Nevaî’nin "bolmasun” redifli gazeli geleneksel yedi beyitten ibarettir ve konusu aşktır. Gazel, Özbek klâsik şiirinde en çok kullanılan remeli müsemmeni mahzuf, yani "fấilâtün/fâ'ilâtün/fâ'ilâtün/fâ'ilün" (taktisi: - v - - /- v - - /- v - - /- v -) vezniyle yazılmıştır. Redifte saf Özbekçe kelime (“bolmasun”) kullanılmıştır. Kafiyede gelen kelimelerin ikisi ("bore - sari”) Özbekçe, beşi ("bahare-cuybarehar hare-şahsuvare-guzare") Farsça, biri de ("ğubare”) Arapçadır. İlk beyit kendi arasında kafiyeli, diğer beyitlerin ikinci mısraları da matlaya göre kafiyelidir. Yani gazelin kafiye dizilişi a-a, b-a, c-a, ç-a, d-a, e-a, f-a şeklindedir.

Azerbaycan şairi Sadık Bey Sadıkî Ali Şir Nevâ̂’nin bu gazeline nazire yazarken hem aynı redif, vezin ve gâyeyi kullanmış hem de orijinal bir eser yaratmayı başarmıştır. İki gazel arasındaki farka gelince, nazire olan gazelde beyit sayısı altıdır, kafiye tertibi de biraz farklıdır. Sadıkî naziresinde kafiye olarak "ğubare", "guzare", "cuybare" kelimelerini kullanır. Aynı zamanda "şarare", "perdedare", "intizare", "perestkare”, "kenare" gibi kelimeleri de kendi üslubunu yaratmak için kullanır. Sadıkî'nin gazelin son beytindeki mısraları da kafiyeli yapması onun yüksek maharet sahibi ve orijinal bir sanatçı olduğunu ortaya koymaktadır. Sadıkî gazelinin kafiye dizilişis; a-a, b-a, c-a, ç-a, d-a, a-a şeklindedir.

Nevaî, gazelinin matlasında Allah'a yönelerek “ol gülge”, yani yârine gam rüzgârından toz bile konmamasını ister. Lirik kahramanın kalbi sevgilisine karşı aşkla dopdoludur ve o yârsız dünya bahçesinde baharın da olmamasını diler. İlk beyitte nida(Ya Rab), istiare (gül, gam yeli, dahr bağı), tenasüp (gül, bağ) ve gulu' (gülge gam yelidin gubar hem tegmasun, usiz dehr bağıda bahar bolmasun) gibi edebî sanatlar mısraların tazeliğini sağlamış, sanatsallığını arttırmıştır.

Azerbaycan şairi de yârine karşı sadakat sahibidir. Sadece sevgilisinin ayaklarının dokunduğu toprağı gözüne sürmeyi arzu eder. Sadıkî, matlanın ikinci mısrasında yârini padişaha benzeterek onun sokağından geçme sadakatini 
sadece lirik kahramana nasip etmesini teşbih, tekrir, tebliğ gibi edebî sanatlarla ifade eder:

Nevaî:

G'am yelidin, yo Rab, ul gulga g'ubore bo'lmasun,

Balki onsiz dahr bog'ida bahore bo'lmasun (Navoiy 1987a: 550).

\section{Sadıkî:}

Gözə ol şəh yolidin özgə gubari bolmasun,

Məndin özgə kimsəgə andin güzari bolmasun (Әfşar 2010: 49).

İkinci beyitte yârinin uzun ömürlü olmasını arzulayan Özbek şairi onun letafet bahçesinde yetişmiş selvi gibi dik endamına her zaman çeşme-i hayvan, yani dirilik suyu arıkından hayat suyu geldiğini hüsnü te'lil sanatıyla ortaya koyar. Azerbaycanlı sanatçıysa sevgilisinin çiçeklerle dolu mekânda büyüyen selvi gibi endamının meyvesini kendi göz yaşlarıyla yıkamayı temenni etmekle gulu' sanatını ortaya çıkarmaktadır:

\section{Nevaî:}

Qaddining sarvig'akim, bog'i latofat naxlidur,

Chashmayi hayvondin o'zga jo‘ybore bo'lmasun (Navoiy 1987a: 550).

\section{Sadıkî:}

Gülşəni-kuyində kim, sərvi-qədi məvasidür,

Hər tərəf əşkimdin özgə cuybari bolmasun (Ofşar 2010: 49).

Nevaî, güzel yârinin yüzünün her zaman bir gül gibi gülmesini ister. Ama yârinin gönlüne gam dikenleri batmasın der (tezat sanatı). Sadıkî de Özbek şairinden farklı olarak Tanrı'ya yönelir ve hicranın gönül evini boşuna yakmamasını diler (nida sanatı):

\section{Nevaî:}

Ayshu ishrat jomidin bo'lsun yuzi gul-gul, va lek

Ko'ngliga g'am gulbunidin xor-xore bo'lmasun (Navoiy 1987a: 550) .

\section{Sadıkî:}

Köyməsün könlü mevün bivəch, ya Rəb, hicr odu, Təndə bərqi-vəsldin özgə şərarı bolmasun (Ofşar 2010: 49). 
Özbek şairine göre sevgilisi güzellikte ve letafette eşsizdir. Yârinin dünya güzelleri yarışmasında hepsinin şahı ve öncüsü olacağına inanır (ığrak sanatı). Azerbaycan şairi de sevgilisini herkesten kıskanır ve ziyafet hareminde âşıktan başkalarının sevgilisiyle muhatap olmamasını ister. Sadece tan şebnemi yâr cemaline perde olabilir (teşhis sanatı) der:

\section{Nevaî:}

Jilva soz o'lg'onda maydon ichra chobuk sho'xlar,

Shohu sarxayl andin o'zga shahsuvore bo'lmasun (Navoiy 1987a: 550).

\section{Sadıkî:}

Məndin özgə bolmasun məhrəm hərimi-bəzmdə,

Tən nəmidin özgə onda pərdədarı bolmasun (Đfşar 2010: 49).

Hazret Nevâ̂’ye göre, âşığın kalbindeki aşk öyle hâl almış ki o canından bile aziz tuttuğu yâri için her türlü belaya hazırdır. Lirik kahraman refiğe yönelerek (nida sanat1), "Eğer yârin başından sadaka yapmak gerekirse benden başkasının bu saadete kavuşmamasını dilerim”, der (hüsnü ta'lil sanatı). Sadıkî de refiğe yönelerek: "Katlin için gelen yârin yolunu gözle dersin, başıma her ne felaket gelse de ol meleği bekletmeyeyim" (hüsnü ta'lil, iştikak sanatları), diye lütfeder:

\section{Nevaî:}

Gar buyursang sadqa boshig'a evurmak, ey rafiq,

Budur ummedimki, mendin o'zga bore bo'Imasun (Navoiy 1987a: 550).

\section{Sadıkî:}

Müntəzir bolkim, gəlür qətlünğə dersən, ey rəfiq,

Hər nə bolsa-bolsun, əmma intizarı bolmasun (Әfşar 2010: 49).

Gazelin son beytinde Özbek şairi kendine güzel yüzlünün canı için dua etmeyi tavsiye ederek (nida sanatı), yârin hizmetinden gayri bir işi ihtiyar etmemesini tembihler. Beyitte gelen "kulluk" kelimesi insanı şüpheye koymaktadır. Bundan kasıt Allah'a "kulluk" mu yoksa "hizmet"mi? Yani burada îhâm sanatının güzel bir örneği kullanılmıştır. Sadıkî naziresinin son beytinde ileri sürülen fikir, Nevaî'nin demek istedikleriyle aynıdır. Tasvire göre, Azerbaycan şairine yâr ziyafetinin hizmetçisi olma görevi verilir. Ama vefalı âşığın eğlencelere meyilden uzak durması lâzımdır: 


\section{Nevaî:}

Ey Navoiy, qil duo jonig'avu jahd aylakim,

Mayling oning qullug'idin o'zga sori bo'lmasun (Navoiy 1987a: 550).

\section{Sadıkî:}

Dedikim, bəzmində bolsun pərəstkarı, Sadiqi,

Leyk meyli-işrətü busü kənarı bolmasun (Ofşar 2010: 49).

\section{Sonuç}

Yukarıdakilerden özetle, Ali Şir Nevaî’nin gelenekleri Azerbaycan şairleri için birkaç yüzyıldan beridir esin kaynağı olmuştur. Bunu, Nevaî’den esinlenen Sadık Bey Sadıkî’nin yazdığı nazire gazeller örneğinde görmekteyiz. Sadıkî, Nevaî gazellerindeki konu ve gâyeyi yeniden ele alarak Azerbaycan klâsik şiirinin gelişmesine katkı sağlamıştır. 


\section{Kaynakça}

Navoiy, Alisher (1987a), Mukammal asarlar to 'plami. Yigirma tomlik. Birinchi tom. Badoyi' ul-bidoya. Toshkent: Fan.

Navoiy, Alisher (1987b), Mukammal asarlar to'plami. Yigirma tomlik. Uchinchi tom. Xazoyin ul-maoniy. G'aroyib us-sig'ar. Toshkent: Fan.

Nağıyeva, Cənnət (2001), Azərbaycanda Nəvai. Bak1: Tural-Ә.

Çınarcı, Mehmet Nuri (2012), "Sâdıkî-i Efşârın Tebriz Milli Kütüphanesindeki Külliyatı ve Türkçe Manzumeleri”, Turkish Studies, Volume 7/3, Summer, S. 813-835.

Gandjei, Turhan (1971), “Sadıkî Afşar'ın Türkçe şiirleri”, Türkiyat Mecmuası, XVI, S.19-26.

Hikmət, İsmayıl (1926), Nəvai və türk ədəbiyyatı. Bakı: Maarif işçisi.

Tərbiyat, Məhəmmədəli (1987), Danişməndani Azərbaycan. Bakı: Azərnəşr.

Muradova, Məntiqa (1999), Sadiq bəy Sadiqinin həyat və yaradıcılı̆̆ı. Bakı: Elm.

Әfşar, Sadiq Bəy (2008), Məcməül-Xəvas, nəşrə hazırlayan: Đkrəm Bağırov. Bakı: Elm.

Әfşar, Sadiq Bəy (2010), Şeirlər, nəşrə hazırlayan: Paşa Kərimov. Bakı: Nurlan. 